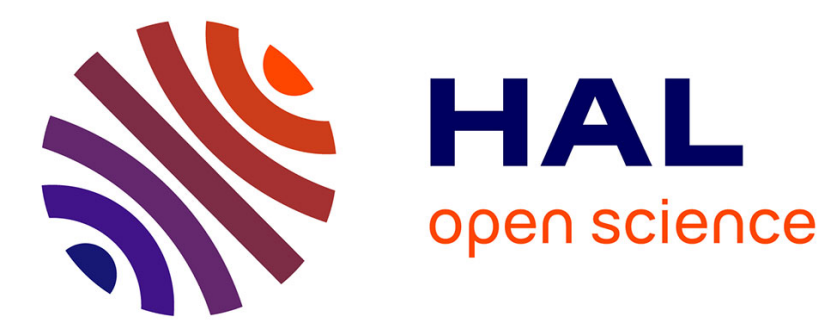

\title{
Terahertz multispectral imaging by thermo-conversion using MIM antenna
}

\author{
Arthur Salmon, Patrick Bouchon, Sylvain Rommeluère, P. Fauché, J.P. \\ Caumes, Riad Haidar
}

\section{- To cite this version:}

Arthur Salmon, Patrick Bouchon, Sylvain Rommeluère, P. Fauché, J.P. Caumes, et al.. Terahertz multispectral imaging by thermo-conversion using MIM antenna. IRMMW-THz, Sep 2018, NAGOYA, Japan. hal-02176341

\section{HAL Id: hal-02176341 \\ https://hal.science/hal-02176341}

Submitted on 8 Jul 2019

HAL is a multi-disciplinary open access archive for the deposit and dissemination of scientific research documents, whether they are published or not. The documents may come from teaching and research institutions in France or abroad, or from public or private research centers.
L'archive ouverte pluridisciplinaire HAL, est destinée au dépôt et à la diffusion de documents scientifiques de niveau recherche, publiés ou non, émanant des établissements d'enseignement et de recherche français ou étrangers, des laboratoires publics ou privés. 


\title{
Terahertz multispectral imaging by thermo-conversion using MIM antenna
}

\author{
A. Salmon ${ }^{1}$, P. Bouchon ${ }^{1}$, S. Rommeluère ${ }^{1}$, P. Fauché ${ }^{2}$, J-P. Caumes ${ }^{2}$ and R. Haïdar ${ }^{1}$ \\ ${ }^{1}$ DOTA, ONERA, Université Paris Saclay, F-91123 Palaiseau - France \\ ${ }^{2}$ Nethis, New Terahertz Imaging Systems, Mérignac, France
}

\begin{abstract}
Conversion of terahertz radiation into thermal radiation is a low-cost approach for terahertz detection by standard infrared camera. In this work, THz $\rightarrow$ IR thermoconversion is performed by the combination of a $\mathrm{THz}$ absorber made of MIM antenna and an emissive layer made of carbon nanotubes. Structural and optical characterizations of the membrane are done, and multispectral imaging in the terahertz range is demonstrated.
\end{abstract}

\section{INTRODUCTION}

$\mathrm{T}$ ERAHERTZ (THz) detectors usually suffer from their high cost, low sensitivity and low spectral selectivity. An alternative detection method is the thermo-conversion of the $\mathrm{THz}$ light into thermal IR radiation by a membrane imaged by a standard IR camera [1] (see Figure 1). This technique advantageously extends the detection range of IR camera towards the $\mathrm{THz}$ spectral range at a relatively low-cost. However, increasing the sensitivity of the technique is required to compete with other detectors (e.g. microbolometers, CMOS). In this frame, increasing the $\mathrm{THz}$ absorption, the IR emission and reducing the membrane thickness are possible ways to increase the $\mathrm{THz} \rightarrow \mathrm{IR}$ conversion efficiency.

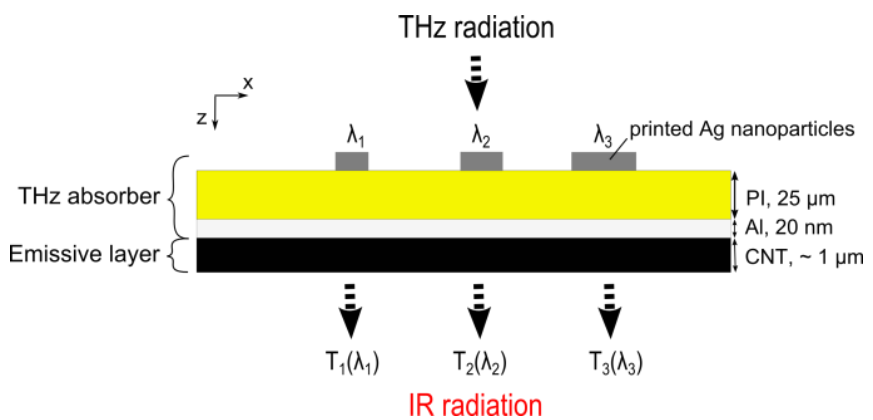

Fig. 1. Principle of the multispectral $\mathrm{THz} \rightarrow \mathrm{IR}:$ the $\mathrm{THz}$ incident light is absorbed by the grating of MIM antenna at a resonance wavelength, and subsequent black body radiation coming from the emissive layer is captured by a standard IR camera - PI: polyimide, Al: aluminum, CNT: carbon nanotubes

In this work, a thin membrane composed of a $\mathrm{THz}$ absorber and an emissive layer is designed. The absorber is a metasurface composed of Metal-Insulator-Metal (MIM) antenna with sub-wavelength dimensions which exhibit a nearly total absorption of the incident radiation at a resonance frequency. The resonance wavelength can be tuned by adjusting the dimensions of the antenna as shown in Figure 2 and Refs [2,3]. This feature allows to provide an array of antenna with different optical responses for multispectral imaging. The emissive layer is a suspension of carbon nanotubes (CNT) deposed on the metallic mirror of the structure. The aim of this work is to characterize the structure and the optical response of the fabricated membrane and to demonstrate $\mathrm{THz}$ detection using the MIM-based membrane.

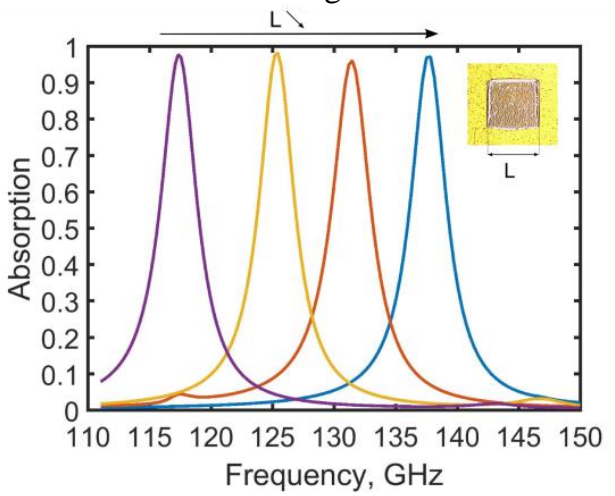

Fig. 2. Calculated absorption spectra of square MIM antenna with size length $\mathrm{L}$ ranging from $600 \mu \mathrm{m}$ to $690 \mu \mathrm{m}$.

\section{EXPERIMENTAL SETUP}

Figure 3.a shows a photograph of the fabricated structure. A grating of $10 \times 15$ square MIM antenna is printed by a Dimatix printer (DMP2800, Fujifilm) on a polyimide sheet metallized with aluminum, as depicted in Figure 1. The printer is equipped with a cartridge (DMC100-01, Fujifilm, 1pL) filled with a dispersion of silver nanoparticles optimized for printing on polyimide. Ink droplets are formed at the nozzle aperture $(\phi=9 \mu \mathrm{m})$ by applying a voltage to the piezoelectric actuator [4]. The voltage waveform was optimized to form a droplet with minimal velocity of about $6 \mathrm{~m} / \mathrm{s}$ as determined from drop watcher images. The printed samples were then sintered for $10 \mathrm{sec}$ at $250^{\circ} \mathrm{C}$ on a hot plate. On the rear face, $20 \mu \mathrm{L}$ drops of carbon nanotubes ink were deposed using a micropipette.
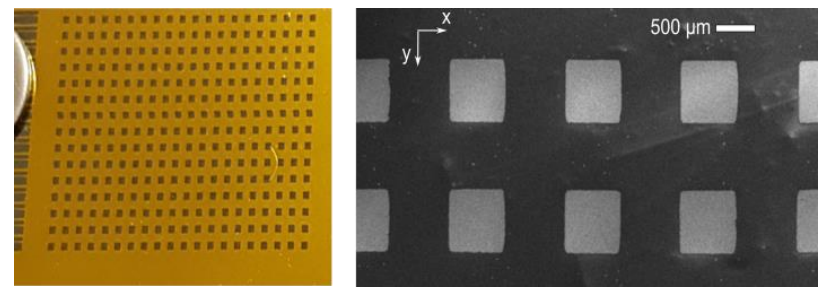

Fig. 3. (a) Photograph of the printed MIM metasurface, and (b) SEM image of the printed structure

\section{STRUCTURAL CHARACTERIZATION}

The printed structure is characterized by scanning electron microscopy (Figure 3.b) and optical microscopy. Figure 4 shows the roughness and dimension distributions of the square MIM antenna determined from the optical micrographs. The dimensions of the antenna follow a Gaussian law centered at $675 \mu \mathrm{m}$ with $16 \mu \mathrm{m}$ FWHM. As a comparison Walther et al. 
[5] printed a 10 x 10 array of U-shaped Split-Ring-Resonators (SRR) on a similar substrate. Under their operating conditions, a significant dispersion on the length of the SRR was reported $(\mathrm{FWHM}=60 \mu \mathrm{m})$. The present operating conditions thus allow a more accurate control of the dimensions of the fabricated pattern.
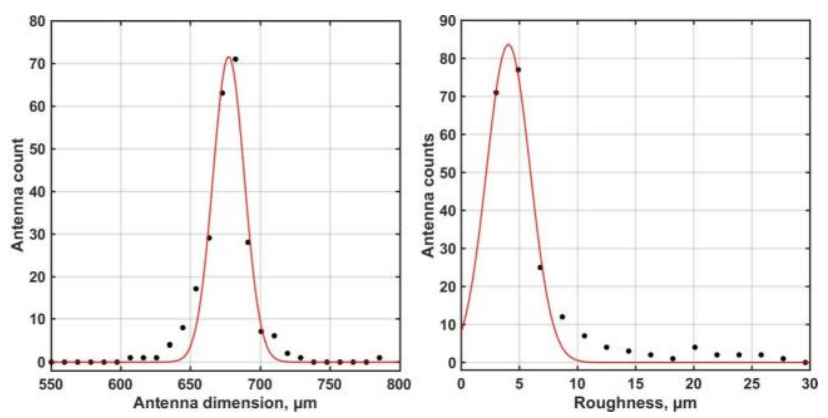

Fig. 4. Distributions of (left) the side length and (right) surface roughness of the $15 \times 10$ array of printed MIM antenna fitted by Gaussian curves.

\section{DEMONSTRATION OF CONVERSION}

Two IMPATT diodes (Terasense, $96 \mathrm{~mW} @ 96 \mathrm{GHz}$, and 17 $\mathrm{mW} @ 142 \mathrm{GHz}$ ) are used to study the optical response of the membrane. The membrane is illuminated by the terahertz sources and the temperature increase of the membrane is recorded by an infrared camera (FLIR SC7000). Figure 5 shows two images recorded when the sample is exposed to the radiation at $96 \mathrm{GHz}$ (5.a) and $142 \mathrm{GHz}$ (5.b). Local increase of the thermal radiation is due to the absorption of the $\mathrm{THz}$ radiation by each individual square MIM antenna. This confirms the ability of the MIM-based membrane to convert the terahertz radiation into thermal radiation. However, the broad spectral response of the membrane is rather unexpected, because of the good control of the printed MIM dimensions, and requires further investigations.
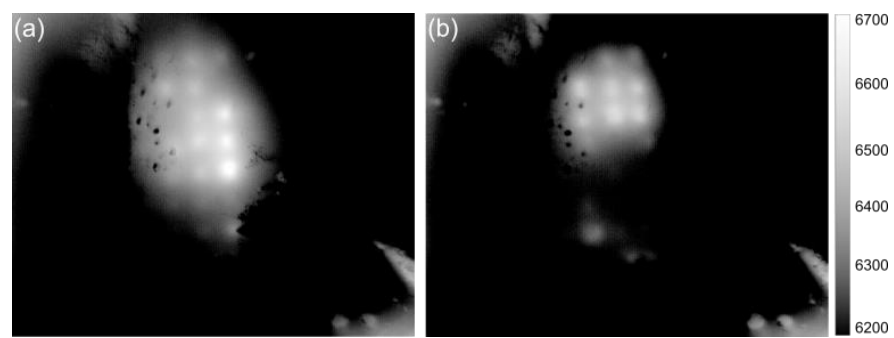

Fig. 5. IR image of the conversion membrane illuminated by terahertz radiation at (a) $96 \mathrm{GHz}$ and (b) $142 \mathrm{GHz}$ - exposure time $=2 \mathrm{~ms}$

\section{CONCLUSIONS}

In this work we have demonstrated the fabrication of a $\mathrm{THz} \rightarrow \mathrm{IR}$ conversion membrane based on a $\mathrm{THz}$ absorber made of a grating of MIM antennas and an emissive layer of CNT. The THz absorber is fabricated by inkjet printing of silver nanoparticles on a polyimide sheet. Structural characterization shows a good control of the antenna dimensions and roughness. In addition conversion has been demonstrated using two IMPATT diodes radiating at $96 \mathrm{GHz}$ and $142 \mathrm{GHz}$.

\section{REFERENCES}

[1] A. Jolly, B. Chassagne and J-C Jolly, Optics Communications 311 (2013) 325-331

[2] P. Bouchon, C. Koechlin, F. Pardo, R. Haïdar and J-L. Pelouard, Optics letters, vol. 37, No. 6, March 15, 2012

[3] M. Makhsiyan, P. Bouchon, J. Jaeck, J-L. Pelouard and R. Haïdar, App. Phys. Lett., 107, 251103 (2015)

[4] E Tekin, P J Smith, and U S Schubert, Soft Matter, 2008, 4, 703-713

[5] M Walther, A Ortner, H Meier, U Löffelmann, P J Smith, and J G

Korvink, Appl. Phys. Lett. 95, 251107 (2009) 